\title{
GENDER EFFECTS ON LANE CHANGE TEST (LCT) PERFORMANCE
}

\author{
Tibor Petzoldt, Nina Bär, \& Josef F. Krems \\ Chemnitz University of Technology \\ Chemnitz, Germany \\ Email: tibor.petzoldt@phil.tu-chemnitz.de
}

\begin{abstract}
Summary: There are various easy-to-implement, low-cost methodologies for evaluating driver performance under distraction caused by in-vehicle tasks. One of them is the Lane Change Test (LCT), which is currently under consideration for becoming an ISO-standardized procedure. This paper investigates the effect of gender on LCT performance. Although a common procedure in psychological research, balancing for gender is not a requirement made by the ISO draft. However, using data from three LCT experiments, we found gender differences in LCT as well as secondary task performance. We conclude that subject samples balanced for gender are necessary to assure comparability of LCT results.
\end{abstract}

\section{INTRODUCTION}

It is a well known fact that driver distraction can cause critical deterioration of driving performance. There is lots of evidence from experimental and field studies illustrating its impact on lateral position, speed maintenance, reaction times, and gap acceptance (see Young, Regan, \& Hammer, 2003 for an overview). Field research (Klauer et al., 2006) and crash statistics (Kuratorium für Verkehrssicherheit, 2008; New Zealand Ministry of Transport, 2007) also show that distraction is a major factor in traffic accidents. As new in-vehicle information systems become increasingly popular, they represent one important source of driver distraction (Young, Regan, \& Hammer, 2003). Therefore, the assessment of the potential distraction caused by such devices becomes a pressing need for the industry as well as authorities.

To tackle this problem, a set of easy-to-use methods has been developed in various projects (ADAM, CAMP , ...) to measure the amount of distraction imposed by performing secondary tasks while driving. One of them is the Lane Change Test (LCT; Mattes, 2003). This test "is a dual-task method that is intended to estimate secondary task demand on the driver resulting from the operation of an in-vehicle device in a laboratory setting. The method is simple and inexpensive so that it can be used by vehicle manufacturers, in-vehicle device manufacturers, and other organizations" (ISO TC 22/SC 13 WG 8, 2008, p. v). The test is currently under review by an ISO workgroup for becoming an ISO standard. It basically uses a simple simulation of a driving scene, wherein the amount of distraction is assessed through the lane change performance in response to signs demanding such a change of lanes. Performance is usually measured in terms of the Mean DEViation (MDEV) from a normative path, as well as composite measures like the ratio of MDEV while performing a secondary task to MDEV without secondary task.

Although the LCT is becoming more widely used as a tool, there are some problems yet to be solved. Despite a setup according to recommendations of the current ISO draft, MDEV values for baseline drives differ a lot between test sites - mean values range from $\mathrm{MDEV}=0.64$ (Weir, 
Kwok, \& Peak, 2007) to MDEV=1.6 (Rognin, Alidra, Val, Lescaut, \& Chalandon, 2007). Since a standardised procedure is expected to produce similar results under comparable conditions, this fact is quite worrisome for those using the LCT. Some possible explanations to be examined might be differences in the equipment, instructional variations, training effects etc. Another factor with possible impact on LCT performance is gender, which is the focus of this paper. There is evidence for gender effects on driving performance, e.g. differences in longitudinal control (Davies, 1991) or driving errors (De Winter, Wieringa, Kuipers, Mulder, \& Mulder, 2007). Also, there have been found differences in performance on more basic tasks like choice reaction tasks (e.g. Adam et al., 1999), which might share some similarities with certain aspects of the LCT. Interestingly, the current ISO draft does not demand or even recommend a subject sample balanced for gender. It merely expects researchers to record this information. In some LCT studies, gender ratios of 13 to 3 or even 18 to 3 can be found (Harbluk, Burns, Lochner, \& Trbovich, 2007; Burns, Trbovich, Curdie, \& Harbluk, 2005). Such an approach does not violate current ISO recommendations, however is quite unusual in experimental research involving human participants. Other studies do not even report the gender ratio (Rognin et al., 2007). The objective of this paper is therefore to investigate whether gender really does not matter when it comes to performing lane changes while being engaged in a secondary task.

\section{METHOD}

To assess possible gender differences in LCT performance, we use data from three experiments. All the studies used exactly the same hard- and software setup, and included trials that were present in every experiment. Since the LCT is believed to be a robust, reliable method, we use those comparable trials and treat the data as being obtained from one large rather than three smaller samples.

\section{Participants}

Overall, 86 subjects were included in the analyses (35 male, 51 female). Participants ranged in age from 18 to 58 years, with a mean age of 27.4 years (28 years male, 27 years female). All of them held a drivers license. Male subjects had a mean overall mileage of 28,000 $\mathrm{km}(18,500$ after removal of an extreme outlier with $320,000 \mathrm{~km}$ ), female subjects had an average of 12,500 $\mathrm{km}$. None of the participants had previous experience with the LCT.

\section{Material}

Lane Change Test/Task (LCT). The Lane Change Test is designed to be a simple method for assessing driver distraction induced by in-vehicle information systems. Participants have to control a vehicle on a 3-lane road, with no other traffic present, and are commanded to change lanes by and according to signs appearing on both sides of this road. Participants are required to maintain a constant speed of $60 \mathrm{kph}$. Exceeding this limit is not possible. The signs appear around every $150 \mathrm{~m}$, duration between lane changes is therefore around $9 \mathrm{sec}$.

For presentation of the LCT, the desktop setup as described in the ISO draft was employed. We used a standard PC system with a 17" flat screen. To control the vehicle, a MOMO forcefeedback game steering wheel with foot pedals was used (Figure 1). As performance indicators, we computed the common MDEV and MDEV ratio measures. 


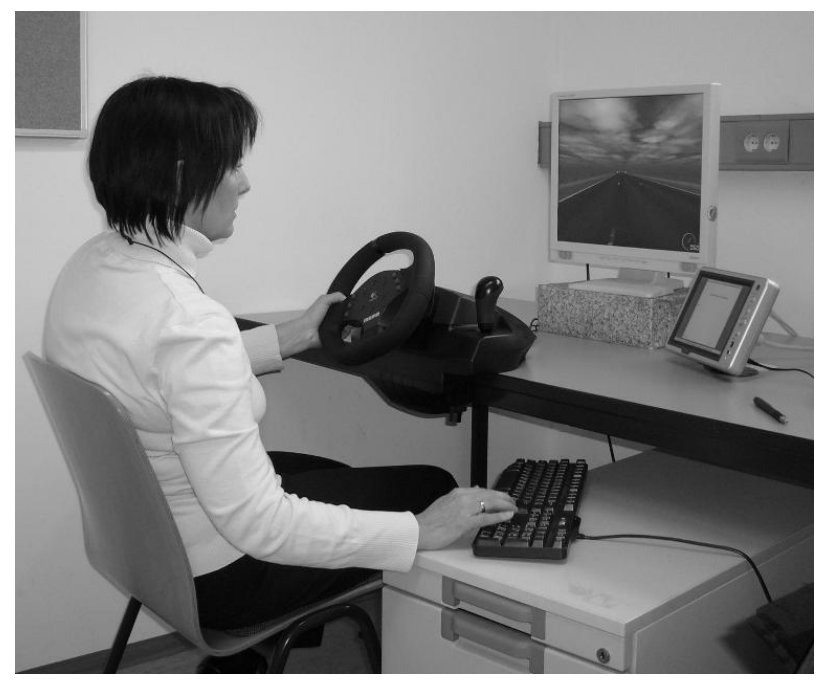

Figure 1. LCT Setup

Critical Tracking Task (CTT). As a secondary task, we used a Critical Tracking Task (Jex, McDonnell, \& Phatak, 1966). The CTT was chosen since it is under discussion for being a suitable calibration task for the LCT. The basic challenge is the manual control of a dynamic unstable element. This element is a simple horizontal bar on an 8.37 " screen that tends to leave the proposed target position at the centre of the screen. While the bar moves up or down permanently, subjects can counter this deviation by using the up and down keys on a keyboard. The task allows for the variation of difficulty by letting the experimenter choose the level of (in-)stability. Three different levels of difficulty were used in our experiments. The standard deviation from the central position is used as a performance indicator.

Driver Attentional Load Index (DALI). For a subjective rating of workload, we employed the DALI questionnaire (Pauzié \& Pachiaudi, 1997). The questionnaire is derived from the NASATLX and intended for the assessment of workload experienced while driving with an additional task. We used four of the questionnaire's seven scales that were suitable for the experimental setup - "global attention demand", "visual demand", "stress" and "temporal demand". Data is available for 68 subjects (two experiments).

\section{Procedure}

Subjects were instructed according to the recommendations of the ISO draft (change lanes as soon as and as fast as possible; try to perform as good as possible in both tasks). After a short familiarization phase, a baseline drive (LCT only) was conducted. After that, three CTT trials (LCT + CTT) were driven, where the different CTT conditions appeared in randomized order. In two of the experiments, each trial (including baseline) was followed by the DALI. After the CTT block, other conditions (different between experiments, not included in the analyses for this paper) followed. 


\section{RESULTS}

When using a quasi-experimental approach, there usually is the chance of having moderator variables produce a fair amount of variation. For the LCT, driving experience, computer use and computer gaming experience might be factors that influence performance in a systematic way. As for computer use, there was no difference between the two groups (male 3.5, female 3.25 hours a day). Concerning gaming experience, most of the subjects (male $60 \%$, female $84 \%$ ) reported that they play computer games less than once a month. However, since there was some difference between male and female subjects, we tested for correlations between this factor and the dependent variables (MDEV and MDEV ratio). No significant correlation for any of the secondary task trials was found. We also tested for correlations between driving experience and the dependent measures, since male and female subjects differed in lifetime mileage. Again, no significant correlation could be found.

\section{Lane Change Test (LCT)}

$M D E V$. As a first measure of performance, we analysed the mean deviation of the driven course from the normative model (MDEV) by calculating a two-way ANOVA for mixed designs. As the Mauchly-Test showed a violation of the sphericity assumption, df were adjusted via Greenhouse-Geisser. The analysis revealed a main effect of secondary task condition $\left(\mathrm{F}_{(3,252)}=73.415, \mathrm{p}<.001\right)$. Also, we found a main effect of gender $\left(\mathrm{F}_{(1,84)}=6.024, \mathrm{p}=.016\right)$. Men seemed better to be able to change lanes as quickly and accurately as possible. Finally, there was an interaction between secondary task condition and gender $\left(F_{(3,252)}=3.165, p=.038\right)$. As can be seen in Figure 2, this effect is largely a result of the baseline performance being on a comparable level for both sexes, whereas the other conditions seem to differ significantly. Posthoc analysis did indeed show significant differences between the sexes for CTT1 $\left(\mathrm{t}_{(84)}=-3.512\right.$, $\mathrm{p}=.001)$ and CTT2 $\left(\mathrm{t}_{(84)}=-2.629, \mathrm{p}=.010\right)$, whereas no significant difference for the baseline or CTT3 could be found.
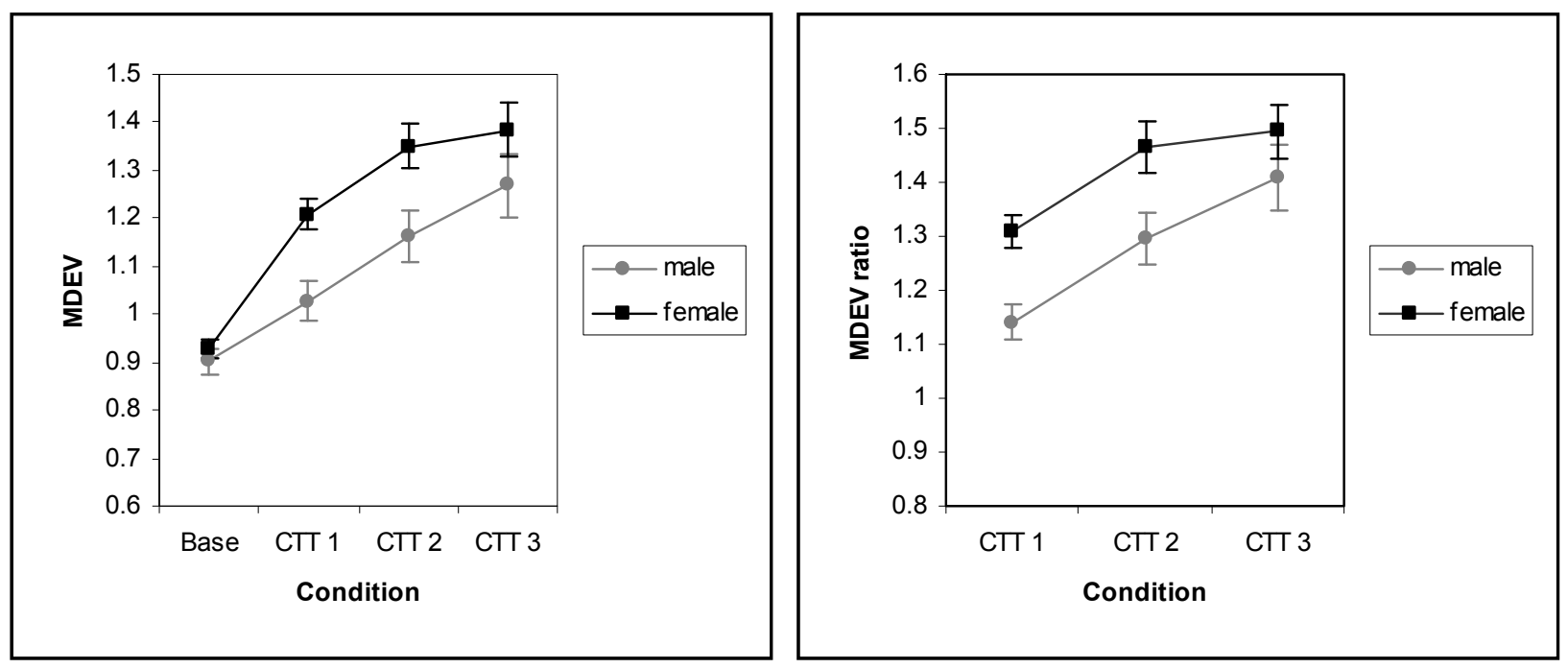

Figure 2. MDEV \& MDEV ratio values in the LCT 
$M D E V$ ratio. For the MDEV ratio, a measure composed of MDEV values in trials with secondary task compared to baseline MDEV values, a similar picture emerges. Again, we found a main effect of secondary task condition $\left(\mathrm{F}_{(2,168)}=30.120, \mathrm{p}<.001\right)$. And, again there was the main effect of gender $\left(\mathrm{F}_{(1,84)}=6.083, \mathrm{p}=.016\right)$. However, we found no interaction between secondary task condition and gender (Figure 2). Post-hoc analysis did again reveal significant differences between the sexes for CTT1 $\left(\mathrm{t}_{(84)}=-3.699, \mathrm{p}<.001\right)$ and CTT2 $\left(\mathrm{t}_{(84)}=-2.380\right.$, $\mathrm{p}=.020)$. No significant difference for CTT3 was found.

\section{Critical Tracking Task (CTT)}

A first idea when finding substantial differences in primary task performance is to look for possible differences in the secondary task that might explain results in terms of different strategies (e.g. different allocation of attention). If this would be the case, one would expect women to outperform men in the CTT. Again, a two-way ANOVA for mixed designs was calculated to address this issue. The analysis showed an effect of secondary task condition $\left(\mathrm{F}_{(2,168)}=385.810, \mathrm{p}<.001\right)$. Also, we found a main effect of gender $\left(\mathrm{F}_{(1,84)}=4.487, \mathrm{p}=.037\right)$. However, it was again the men that produced overall better results than the women (Figure 3).

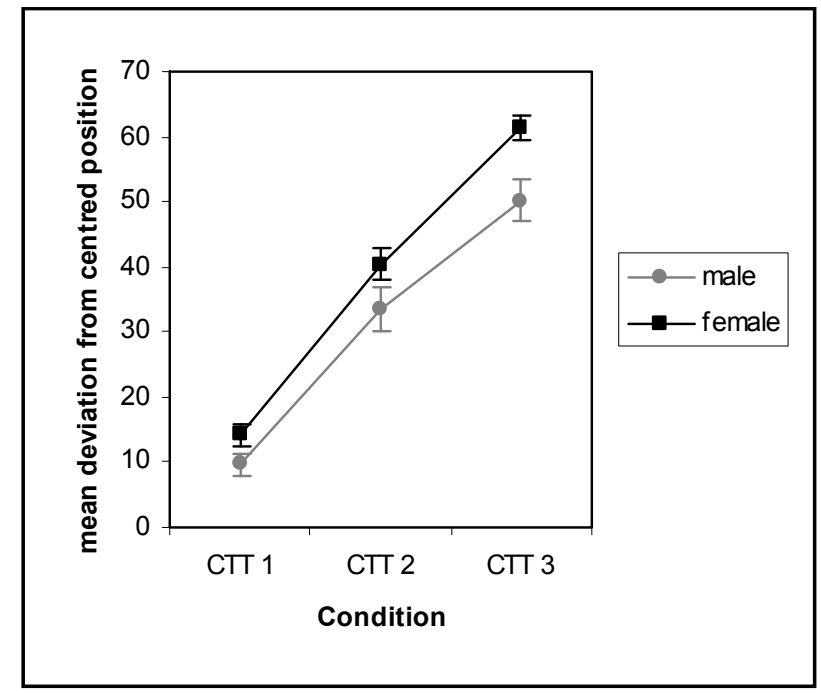

Figure 3. Mean deviation from centred position in the CTT

\section{Driver Attentional Load Index (DALI)}

To analyse the subjective data, we calculated a two-way ANOVA for mixed designs for each of the subscales. Mean values (Table 1) seem to follow the same pattern as the data from the objective measures. For the secondary task condition, all subscales produced highly significant results ("global attention demand": $\mathrm{F}_{(3,198)}=50.541$, "visual demand": $\mathrm{F}_{(3,198)}=46.924$, "stress": $\mathrm{F}_{(3,198)}=56.987$, "temporal demand": $\mathrm{F}_{(3,198)}=68.294$; all $\left.\mathrm{p}<.001\right)$. However, only for the rating of "visual demand" we found a marginally significant difference between the two sexes $\left(\mathrm{F}_{(1,66)}=3.840, \mathrm{p}=.054\right)$. Differences on all other scales did not reach statistical significance (from $\mathrm{p}=.303$ to $\mathrm{p}=.381$ ). We also found no interaction between secondary task condition and gender. 
Table 1. Mean DALI values

\begin{tabular}{lcccccccc}
\hline \multirow{2}{*}{ Subscale } & \multicolumn{4}{c}{ male } & \multicolumn{4}{c}{ female } \\
\cline { 2 - 10 } & Base & CTT1 & CTT2 & CTT3 & Base & CTT1 & CTT2 & CTT3 \\
\hline Global attention demand & 3.48 & 4.38 & 4.97 & 5.72 & 3.97 & 4.56 & 5.28 & 5.54 \\
\hline Visual demand & 3.55 & 3.97 & 5.10 & 5.17 & 3.92 & 4.54 & 5.49 & 5.44 \\
\hline Stress & 2.38 & 3.31 & 4.41 & 4.69 & 2.95 & 3.62 & 4.67 & 4.54 \\
\hline Temporal demand & 2.03 & 3.14 & 4.24 & 4.38 & 2.44 & 3.49 & 4.54 & 4.44 \\
\hline
\end{tabular}

\section{CONCLUSIONS}

The analyses done in this study have shown that gender does have an undeniable effect on LCT performance. Men seem to be better "lane changers" than women, at least in this artificial laboratory task. Moreover, this difference in performance is not simply a result of differences in attention allocation between the two tasks at hand. The men's superior secondary task performance does not allow for such an interpretation. Even when looking at the subjective measures, one might be inclined to believe that women did have a harder time in carrying out the two tasks in parallel (although statistical analysis provided no confirmation). Also, we were able to show that variables that might be suspected to moderate gender differences in the task at hand are not responsible for the obtained results.

Considering the common practice in experimental psychology of balancing for gender whenever possible, it is somewhat striking that the current ISO-draft does neither demand nor recommend such a balancing. This flaw really becomes an issue when taking into account the results of our analyses. Whether gender is a causal factor that is directly linked to performance, or rather correlated to other influential factors like experience in carrying out secondary tasks while driving or similar, remains a matter of speculation and maybe further investigation. However, when thinking about practical implications of our results, gender should be the factor for users of the LCT to focus on. Gender is obviously much easier to observe than any other possible contributing variable, making a "screening" for this factor a very simple process. In addition, given the dichotomy of male/female, balancing for gender is equally simple, whereas controlling factors like any kind of experience might require more demanding procedures. Therefore, while other factors might be those directly responsible for the observed differences in performance, in terms of usability of the LCT as a robust, easy to employ method for assessing driver distraction, balancing for gender appears to be the best way to eliminate a large amount of unwanted variation.

\section{REFERENCES}

Adam, J., Paas, F., Buekers, M., Wuyts, I., Spijkers, W., \& Wallmeyer, P. (1999). Gender differences in choice reaction time: Evidence for differential strategies. Ergonomics, 42(2), 327-335.

Burns, P.C., Trbovich, P.L., McCurdie, T., \& Harbluk, J.L. (2005). Measuring distraction: Task duration and the lane-change test (LCT). Proceedings of the Human Factors and Ergonomics Society 49th Annual Meeting, Orlando, Florida. 
Davies, D.R. (1991). Determinants of age and sex differences in driving performance: Full research report. ESRC End of Award Report, X202252005. Swindon, UK: ESRC.

De Winter, J., Wieringa, P., Kuipers, J., Mulder, J., \& Mulder, M. (2007). Violations and errors during simulation-based driver training. Ergonomics, 50(1), 138-158.

Harbluk, J.L., Burns, P.C., Lochner, M., \& Trbovich, P.L. (2007). Using the lane-change test (LCT) to assess distraction: Tests of visual-manual and speech-based operation of navigation system interfaces. Proceedings of the 4th International Driving Symposium on Human Factors in Driver Assessment, Training, and Vehicle Design, Stevenson, Washington.

ISO TC 22/SC 13 WG 8 (2008). Road vehicles - Ergonomic aspects of transport information and control systems - Simulated lane change test to assess in-vehicle secondary task demand.

Jex, H.R., McDonnell, J.D., \& Phatak, A.V. (1966). A "critical" tracking task for manual control research. 7th IEEE Symposium on Human Factors in Electronics (HFE), HFE 7, 138-145.

Klauer, S.G., Dingus, T.A., Neale, V.L., Sudweeks, J.D., \& Ramsey, D.J. (2006). The impact of driver inattention on near-crash/crash risk: An analysis using the 100-car naturalistic driving study data. US Department of Transportation.report No. DOT HS 81059.

Kuratorium für Verkehrssicherheit (2008). Road accident statistics 2007: Reihe Verkehr in Österreich, Vienna: Author.

Mattes, S. (2003). The lane-change-task as a tool for driver distraction evaluation. In H. Strasser \& K. Kluth \& H. Rausch \& H. Bubb. (Eds.), Quality of work and products in enterprises of the future (pp. 57-60). Stuttgart: Ergonomia.

New Zealand Ministry of Transport (2007). Reported Injury Crashes 2006, Wellington, NZ: Author.

Pauzié, A. \& Pachiaudi, G. (1997). Subjective evaluation of the mental workload in the driving context. In T. Rothengatter \& E. Carbonell (Eds.), Traffic \& Transport Psychology: Theory and Application (pp. 173-182). Oxford: Pergamon.

Rognin, L., Alidra, S., Val, C., Lescaut, A., \& Chalandon, X. (2007). Driver strategies when interacting with information and comfort systems. Proceedings of the $20^{\text {th }}$ International Technical Conference on the Enhanced Safety of Vehicles, Lyon, France.

Weir, D.H., Kwok, A.M., \& Peak, J.L. (2007). Exploratory lane change test experiments in support of ISO WG8 LCT task force. Presentation given at the Meeting of the Task Force Calibration Task, Milano, Italy.

Young, K., Regan, M., \& Hammer, M. (2003). Driver distraction: A review of the literature. MONASH University, Accident Research Centre. 